\title{
RESEARCHING CONSUMER RESEARCH. AN ANALYSIS OF CONSUMER RESEARCHERS IN AUSTRIA WITH SOME IMPLICATIONS FOR THE SCIENTIFIC FIELD AND CONSUMER POLICY ${ }^{1}$
}

\author{
SEBASTIAN NESSEL \\ Karl-Franzens-University of Graz, Department of Sociology, Universitätsstraße 15, 8010 Graz, Austria
}

(C) 2019 Sebastian Nessel

This is an open access article distributed under the Creative Commons Attribution-NonCommercial-NoDerivs license (http://creativecommons.org/licenses/by-nc-nd/3.0/)

DOI: 10.1515/eras-2019-0007

\begin{abstract}
Since over a decade, there are ongoing debates about the relationships between the scientific field of consumer research and the political field of consumer policy. To date, there exist theoretical overviews of the international state of the art in consumer research and its historical developments regarding topics, and theoretical and methodological advancements. There also exist few empirical studies which approached this field through content analysis of scientific articles, case studies or literature reviews. Nonetheless, prior research has yet neglected consumer researchers themselves and, above all, their stances toward consumer policy. To fill this gap, this article seeks to enhance knowledge about consumer researchers by presenting empirical results of a survey among Austrian consumer researchers. In contrast with previous research, this article relates its empirical findings to better understand how consumer research can become a more integrated and institutionalized research area, in Austria and elsewhere. As the results indicate, there are some commonalities in Austrian consumer research which may serve as a fertile ground for a closer integration of the field and which could enhance cooperation between the scientific and the political field. Yet, as this article shows, there also exist some obstacles, which may hinder such efforts. It concludes with some propositions for consumer research as a scientific field and discusses obstacles and prospects of a future collaboration between this scientific field and consumer policy. In doing so, this article seeks to contribute to the debate about a so-called "evidence-based" consumer policy suggesting that consumer policy can draw on a wide array of scientific perspectives and should not restrict itself to behavioural insights alone, a current trend in some European countries and in the European Commission. As will be shown, the Austrian case is furthermore informative to better understand internal and external (political) efforts to foster cooperation within consumer research and the relationship between consumer research and consumer policy.
\end{abstract}

\section{Keywords}

consumer research, consumer policy, sociology of consumption, field analysis

\footnotetext{
${ }^{1}$ The author appreciates a grant of the Austrian Chamber of Labour Vienna to support this study. The empirical part of this study was conducted in cooperation with Michael Jonas and Simeon Hassemer from IHS Vienna and Sandra Pfister from the University of Linz. Special thanks to Sandra Pfister for helping to craft and discuss a preliminary version of this article
} 


\section{Introduction - Researching Consumer Researchers}

The label "consumer research" is commonly used to designate a broad area of research dedicated to all relevant aspects of consumption - its preconditions, the use of goods and services, and the effects of consumption on individuals, households, firms and the economy as a whole. Given that consumption is not a "practice" in its own right but "a moment in every practice" (Warde, 2005, 137), consumer research is carried out by scholars in a variety of disciplines including economics, sociology, psychology, anthropology, history and geography. In some countries, consumer research has been institutionalized in disciplinary associations in the areas of sociology, psychology or marketing. Consumer researchers come together on a transnational level in associations such as the research network on consumption of the European Sociological Association. Organizations such as the Association for Consumer Research or conferences such as the International Consumer Conference only occasionally bring together scholars from different disciplines and backgrounds.

For more than a decade, there have been ongoing debates regarding the relationships between the scientific field of consumer research and the political field of consumer policy. In some European countries (e.g. in Germany or Great Britain), in the European Commission and in international organizations such as the OECD, these debates have contributed to the creation of a so-called "evidence-based consumer policy" and to the establishment of associated scientific "behavioral insight teams", which should provide policymakers with empirical results about consumer behavior (e.g. Hagen et al., 2013; Reisch \& Sandrini, 2015).

In Austria, the debate about the relationship between the political and the scientific fields has only recently emerged. Up until now, Austrian ministries and policymakers hesitated to engage in a deeper dialogue with consumer researchers and obtain information that they could use to ground their decisions, although the first steps in the area of sustainable consumption have been discussed (Hübner et al., 2018), and possible scenarios of future relationships between consumer research and consumer policy have recently been scrutinized (Jonas \& Hassemer, 2018). Still, the debate on the pros and cons of holding deeper dialogues between consumer researchers and consumer policymakers in Austria, as elsewhere, would first and foremost improve if the field of consumer research itself and the expectations of scholars towards politics were better understood. Such insights also contribute to a better understanding of the obstacles and prospects related to a deeper dialogue between those working in the scientific and the political fields, in both Austria and elsewhere.

However, an analysis of the Austrian field of consumer research has not yet been conducted. The same holds true for the international field of consumer research. To date, researchers have produced theoretical overviews of the international state of the art in consumer research and its historical developments, with regard to specific topics and theoretical and methodological advancements (Antonides \& van Raaij, 1998; MacInnes \& Folkes, 2010; Østergaard \& Jantzen, 2002). Few empirical studies exist in which this field was explored by conducting a content analysis of scientific articles (Helgson et al., 1984; Peighambari et al., 2016), case studies (Hirschman, 1985) or literature reviews (MacInnis \& Folkes, 2010). Nonetheless, previous research has neglected the consumer researchers themselves and, above all, their stances towards consumer policy.

In this article, I seek to enhance knowledge about consumer researchers by presenting empirical results of a survey conducted among Austrian consumer researchers. With one exception (Oehler \& Reisch, 2012), this represents the first study on the individual situation of consumer researchers, the field of consumer research in Austria, and the stances taken by consumer researchers toward (consumer) politics. Theoretical and methodological approaches, various resources used to carry out research, different research aims and diverse expectations of these consumer researchers towards politics are described. In contrast with previous research, 
the empirical findings of this study are related to others to increase our understanding of how consumer research can become a more closely integrated and institutionalized research area. Based on this assessment, the prospects for and obstacles to achieving a deeper dialogue between consumer policymakers and consumer researchers are described. As the results indicate, some commonalities in Austrian consumer research which may serve to more closely integrate the field and could enhance cooperation between those working in the scientific and political fields were identified. Still, as shown in this article, some obstacles also exist, which may hinder such efforts.

The remainder of this article is structured as follows: The first section provides a brief overview of the current state of consumer research. The second section outlines the methods and survey sample of Austrian consumer researchers and describes some practical problems related to approaching a relatively unknown scientific field. The empirical results are presented in the third section. The final section presents the results and their implications for consumer research in Austria, considering international experiences and contributions. In this section, I argue that consumer research in Austria is a highly diverse field and that researchers working in this field can contribute to the creation of an evidence-based consumer policy by providing a multitude of theoretical templates and empirical findings about consumer behaviour. The findings of this study indicate that consumer researchers and consumer policymakers should acknowledge the diversity of consumer research approaches, as they are expressions of the flexible and multitudinous subjects addressed in consumer research. As will be shown, the Austrian case also helps researchers better understand internal and external (political) efforts to foster cooperation within the field of consumer research and strengthen relationships between the fields of consumer research and consumer policy.

\section{Consumer research - what is (not) known about this scientific field?}

This section provides a concise overview of consumer research from an international perspective. Given the wide scope of this field of inquiry and the existence of a vast body of relevant literature within the field, I describe theoretical and empirical contributions that emphasize broader developments. In sections three and four, I then scrutinize if and to what extent these developments are replicated in the present empirical study of the Austrian case.

Using the approach taken by Antonides and van Raaij (1998), several stages of consumer research can be identified. Preceded by a "pre-scientific-stage", "single-concept approaches" were the first to be used to systematically study consumption. In their view, the field had been dominated since the 1960s by "grand theories" that were used to analyze consumer behavior within one meta-framework. Since the 1970s, "information-processing approaches" had been developed, which more strongly emphasized the situational effects on purchasing decisions and underscored the usefulness of "middle-range theories". In the 1980s, the field was enriched by the addition of "affective approaches", which underlined the significance of the emotions that were associated with and influenced consumption decisions. In the 1990s, the "experimental approach" built upon the previous approaches by placing a stronger focus on symbolic meanings of consumption, hedonism and expressive value.

Another contribution to the development of consumer research since the 1950s was provided by Ostergaard and Jantzen (2002). The authors developed a five-type framework to differentiate four stages of approaches to consumer research. This framework uses the "consumer metaphorically", the "ontology of consumption", the "character of the subject matter", the "primary method", and the "scientific foundation" as categories (ibid: 11-20). Based on evaluations in each category, the authors identified the "buyer behavior approach" that merely focused on "purchasing" as a first category which had been used since the 1960s. The second is the "consumer behavior" approach, which has been used since the 1970s and 
which analyzed consumer behavior before and after a purchase is made. The third is the "consumer research" approach, and the fourth is the "consumption studies" approach. According to the authors, the latter two have been influential since the 1980s. Whereas the first approach shifts the perspective toward the wider environment of consumption and the consumers' everyday lives, the latter approach is taken to more closely examine consumer culture and the social relations that exist between consumers. As in the above-mentioned analysis conducted by Antonides and van Raaij (1998), Ostergaard and Jantzen emphasized that, up until today, aspects of all accounts have been found within consumer research (see similarly MacInnis \& Folkles, 2009; Simonson et al., 2001). For the purpose of the argument posed in this section, two relevant aspects of their summary are highlighted. First, the perception of the consumer, the ontology of consumption, and the conception of the subject matter have developed from an "internal" biological understanding to an understanding of consumers embedded in and influenced by social structures. Consumers have been increasingly perceived as actors who do not mechanically respond to biological needs but consume products in search of social identity, social recognition or hedonism. Second, the methods used to analyze and understand consumer behavior have diversified and, today, not only encompass experiments or surveys but also qualitative methods (see also Miller, 1995; Simonson et al., 2001). These findings are consistent with the previously mentioned developments identified by Antonides and van Raaij (1998), as well as those mentioned in other overviews, such as those of Arnould and Thompson (2005), Simonson et al. (2001) or Miller (1995).

Apart from the theoretically informed overviews mentioned so far, few studies have been carried out to empirically assess the state of consumer research. Helgeson et al. (1984), for example, analyzed the content of several relevant consumer research journals to identify research trends and methodological accounts. Recently, this study was replicated by Peighambari et al. (2016) for a later period. Both studies provided support for the aforementioned, theory-based overviews and found that the number of research topics and methods used to study consumer behavior had substantially grown. Helgeson et al. $(1984,454)$ argued that these findings indicate the "fragmented nature of the discipline and the apparent lack of [a] consistent direction", rather than suggest that a "programmatic approach" has been taken. In contrast, Hirschman (1985) suggested that different styles of scientific research must be acknowledged. This is exemplified by drawing on four cases of contributions gained by taking different consumer research approaches ("analytical science", "conceptual theory", "conceptual humanism" and "particular humanism"). It is interesting to note that the researchers who perform consumer research have been a neglected topic in all of these studies. To my knowledge, only Oehler and Reisch (2012) conducted such a study.

Oehler and Reisch analyzed consumer research in Germany between 2001 and 2010. They identified 155 scholars working in the field, 98 of whom completed their questionnaire and 69 of whom were included in the final sample because they were identified to conduct consumer research. Their results show the following:

German consumer researchers work on five main topics: "Consumer behavior" $(56 \%)$, "Sustainability" (53\%), "Diet and Health" (47\%), "Internet based Markets/New Technologies/Media" (43\%), and "Providing Information for Consumers", "Consumer Education", and "Labeling" (41 \% respectively). Notably, all other twenty (!) topics that the authors predefined also count high percentages - between twelve ("Data Security") and forty percent ("Special Consumer Groups"). Regarding "important topics", "Consumer Behavior" (56\%), and "Sustainability" (52\%) are the most important, followed by "Consumer Education" (49\%), "Internet based Markets/New Technologies/Media" (47\%), "Labeling" (46\%), and "Financial Services" (44\%). To identify "dominant trends", the authors worked with a questionnaire with open-ended questions and matched the answers to one of thirty predefined 
categories. The significance of the results was unclear, a finding that may have been due to the procedure used, as the responses assigned to each category were few: "Behavioral Economics" (ten responses), "Internet based Markets" (eight responses) and "Financial Markets", "Health/Diet" and "Sustainability" (all having five responses) were named. It would be interesting to know if this result was due to the research strategy taken or because of the diversity of answers, which would suggest a fragmentation of the field as suggested by Simonson et al. (2001). Notably, the questions on "important topics" and "dominant trends" were the only ones which can shed light on the respondents' perceptions of the German field of consumer researcher in a more general way.

Regarding "research traditions", $32 \%$ of their respondents worked in a "Behavioral Economics/Behavioral Finance" tradition; 28\%, in "Sociology/Political Sciences", 22 percent in "Psychology"; and 15\%, in "Institutional Economics" and "Law" respectively. Oehler and Reisch (2012) also found that consumer research in Germany was funded mostly by "board resources" (56\%), political institutions such as the European Union (EU) (29\%), national or federal Ministries (27\%), or consumer organizations (22\%). Finally, the authors asked the respondents what they knew about and how satisfied they were with the consumer research networks that had recently been formed by German ministries (Netzwerk Verbraucherforschung) and federal actors (Netzwerk Verbraucherforschung NRW). Only 54 percent of the respondents were aware of these networks.

The findings of the study by Oehler and Reisch (2012) reveal interesting, initial information about scholars doing consumer research. But several aspects that could shed more light on both the field of consumer research and the researchers were not addressed.

In this study, I address some of these aspects. I examine more closely the research traditions and how the subject matter of consumer research is conceptualized, to determine whether scholars apply a broad (sociological) perspective, taking into account the fact that actors are embedded in a variety of social structures, or have a narrower point of view, concentrating on the cognitive dimensions of consumption as has been suggested by economic and behavioral approaches (Nessel et al., 2018). Moreover, I determine how scholars empirically carry out research, that is, what methods are used. By addressing these questions, an attempt is made to reveal different "worldviews" and "aims" towards research, which may than lead researchers into different "camps" and prohibit the closer integration of consumer research as a field (Simonson et al., 2001). Finally, I take a close look at recent networks that have formed among scholars in Austria and at the scholars' relationships to a variety of nonacademic organizations, such as NGOs, unions or firms, to better reveal the internal structure of the field and its intersections.

\section{Data and Methods}

To analyze the individual situation of consumer researchers in Austria and the field in general, a quantitative survey was used for the purposes of this study. Because consumer research has been described as "living in a diverse set of disciplines" (Deighton, 2007), the first task was to identify the target population for the survey and the population of consumer researchers in Austria. For this purpose, a documentary analysis of the homepages of both academic and non-academic research institutes in Austria was carried out. The analysis included the twelve largest universities in Austria, fourteen polytechnic colleges (Fachhochschulen, FH), five teacher training colleges (Pädagogische Hochschulen, PH), and four independent research institutes. Based on the findings of the documentary analysis, researchers who had minimally obtained a $\mathrm{PhD}$ and had published at least two publications or carried out one research project on consumer-related issues were included in the final sample, which consisted of 376 "consumer researchers". 
Of course, the procedure used to identify the target population is not without certain problems. First, due to limited financial and human resources, not all homepages of public and private academic and non-academic institutes in Austria at which scholars could potentially carry out consumer research were examined. Second, the decision to set a threshold and include researchers with at least two consumer research publications or one related project could be questioned. For the purposes of this initial study, however, this threshold was considered appropriate. Finally, the homepages examined may not contain current information. These types of limitations are characteristic to every study in which a relatively unknown scientific field is explored. For these reasons, deeper statistical interferences of the study findings could not be made (see below).

Once the target population had been identified, an online questionnaire was constructed. This questionnaire differs from those used in previous studies (Helgeson et al. 1984; Oehler \& Reisch 2012; Peighambari et al. 2016) in several ways. Above all, consumer researchers were neither confined within previously defined disciplinary boundaries nor were expected to only select pre-defined research methods or approaches. Furthermore, I operationalized "networking" in a differentiated and broader manner than in previous studies, taking into account not only the knowledge of and membership in networks but also the forms of cooperation among academic scholars, as well as between them and non-academic (NGOs, unions, firms) and political actors (e.g. different ministries, European Union). Finally, scholars were asked to describe their expectations regarding consumer policy.

The questionnaire consists of 111 items which represent five thematic clusters: human and financial resources to carry out consumer research, conduct of research ("research topics", "approaches", "methods"), cooperation, opportunities and constraints of the field of consumer research and preferable future directions ("disciplinary, conceptual and methodological orientation", "political and societal relevance", "institutional settlement"), and sociodemographic items. Most items were structured, and some were left open, especially those addressing the perception of "major gaps in consumer research" as well as the respondents" "conceptualization" and "understanding" of consumer research.

The questionnaire was sent by e-mail to each researcher in the identified target population. Thirty-eight percent of the initial population filled in the questionnaire and 17\% (62 respondents) continued to the last item. Considering the current paucity of knowledge about the target population and the fact that people are generally not motivated to participate in online surveys, a valid response rate of $17 \%$ is considered to be relatively high.

The number of missing values notably varied on some items. Particularly the items addressing the "assessment of the status quo of consumer research" consistently showed more missing values than those addressing the "desirable future directions" of Austrian consumer research. This suggests that consumer researchers indeed have a solid ideational understanding of consumer research but lack knowledge about the existing state of the field (see section three).

The final sample represented 62 "consumer researchers" in Austria, of whom $60 \%$ are male and $40 \%$ are female. The average age of the participants was 50 years. The majority were employed at universities (57\%) and FHs (23\%), with a few employed at non-academic institutes $(15 \%)$ or $\mathrm{PHs}^{2}(5 \%)$, closely reflecting the distribution in the target population. The sample consisted of researchers from a broad variety of disciplinary backgrounds: social sciences $(21 \%)$, economics $(15 \%)$, natural sciences $(10 \%)$, technical sciences $(8 \%)$, educational sciences $(6 \%)$, law (6\%), "life sciences" (6\%) and psychology (2\%) and numerous individual research

\footnotetext{
${ }^{2}$ The FH (Fachhochschulen), are polytechnic colleges; PH (Pädagogische Hochschulen) are teacher training
} colleges. 
areas (26\%). Virtually each respondent in the sample was identified as a "consumer researcher": 94\% mentioned consumer-related aspects as relevant for their research and $40 \%$ defined these as their "main research" area. Therefore, the respondents identified in the sample did indeed understand themselves as "consumer researchers". Note that this result somewhat "corrects" the previously mentioned problems associated with identifying the target population in this study.

The data analysis was descriptive and allowed to analyze frequencies, central tendencies and dispersion. I acknowledge that descriptive analysis is often criticized due to its limitations. However, the purpose for conducting this study was not to test any theories or certain presumptions, but to gain initial insights into the characteristics of consumer researchers in Austria and their perspectives of the field and toward politics. I hence considered the methodological considerations in the tradition of "exploratory data analysis", advanced by John Tukey in the late 1970s, who advocated the resurrection of techniques of descriptive analysis to detect and investigate data. Exploratory data analysis is carried out neither to infer, nor confirm results, but to examine the data structure and allow "looking at data to see what it seems to say" (Tukey 1977, v). Especially if little knowledge about a research object is available, as was the case in this study, drawing on "simple arithmetic and easy-to-draw pictures" (ibid.) seemed a promising way to gain new insights about the relatively unknown field of consumer research in Austria (e.g. about the specialty of a distribution instead of the mere distribution of characteristics within a population). And, as said before, due to the previously unknown nature of consumer researchers in Austria, it was not possible to draw further interferences regarding the empirical results. In this study, hence, I concur with the idea that good description is better than bad explanation.

\section{Consumer Research in Austria - Empirical Results}

In the following sections, I outline the main results of this study: the resources of consumer researchers in Austria (3.1.), the topics studied (3.2), the way consumer research is carried out (3.3), and the "research orientations" and "conceptualizations" of consumer research (3.4.). Attention is then given to structures of cooperation and networks, that is, the relations within the field (3.5). Finally, in section 3.6, the prospects for Austrian consumer research and the respondents' expectations towards politics are examined.

\section{Human and financial resources}

As mentioned previously, most of the respondents work in different academic institutes. Therefore, the finding that most consumer research that has been carried out over the last five years was funded by the institution in which the scholars work $(56 \%)$ was not unexpected. Another 44 percent funded their research by conducting contract research, and 43 percent received grants. ${ }^{3}$ Every third researcher applied for funding from the Austrian Science Fund (basic research funding), the Austrian Research Promotion Agency (applied science funding), the Austrian National Bank or EU frameworks. Thirty-four conducted commissioned research, with political actors being the main funding organizations (34\% on the national and $27 \%$ on the EU level). One interesting finding was that about every fourth scholar reported "self-financing" as the financial basis of their research. Established positions in academic institutes seem to represent a central "financial pillar" supporting consumer research in Austria. Still, the evidence of widespread efforts to apply for external funding and self-financing indicates that there is an increasing pressure on researchers to raise third-party funds.

\footnotetext{
${ }^{3}$ The following numbers are based on valid responses. Due to multiple selections in the questionnaire, numbers can exceed 100 per cent.
} 
After being asked to assess their own financial resources, respondents were asked to generally assess the financial resources in the field of consumer research (see Table 1).

\section{Table 1: Perceived Funding for Consumer Research in Austria}

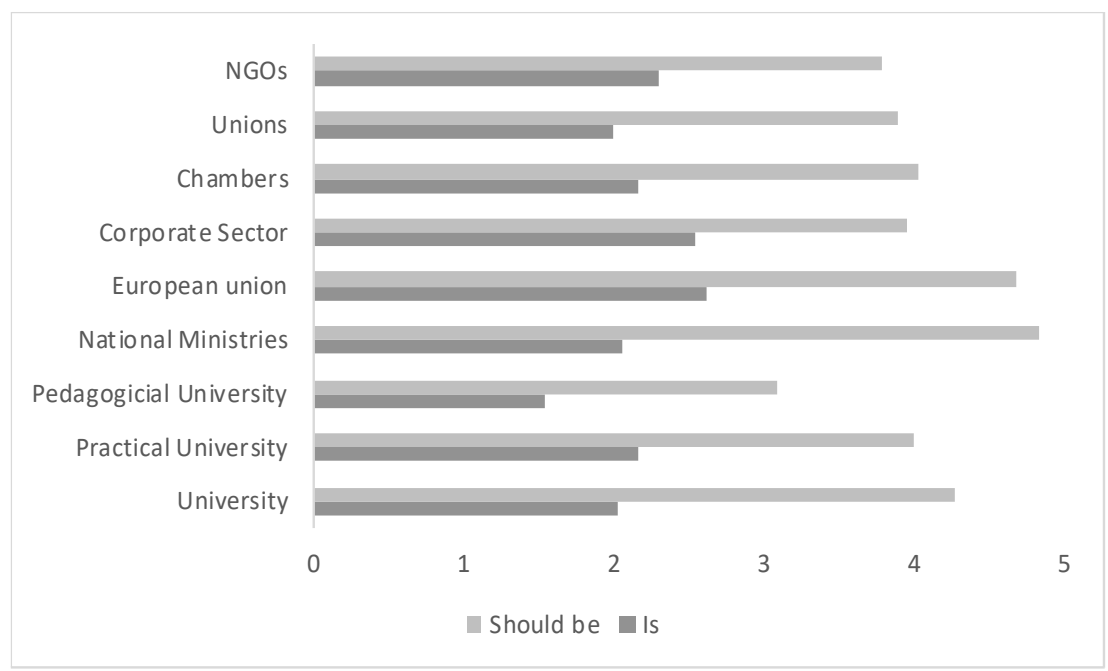

It is hardly surprising that the results show that the overall funding of the field is perceived as insufficient, given the facts that the mean value of agreement for a "sufficient level" of funding is below three ${ }^{4}$ for all possible funders (academic institutions, ministries, EU, firms, chambers, trade unions, NGOs) and the respondents call for extending the amount of funding in each category (see table one). What is surprising is that the highest level of agreement was observed regarding a strong extension of funding by political actors such as the National Ministries $(\mathrm{m}=4.83)$ and the EU $(\mathrm{m}=4.68)$ and not by their own academic institutes. This result indicates that the scholars expect more political support of consumer research in this country (see section four).

Regarding human resources, the results are highly variable. The median and mode of persons available for cooperation is three, but $40 \%$ of the respondents had fewer staff to count on. These numbers suggest that the human resources available to carry out consumer research significantly differ for each Austrian scholar.

\section{Topics in Austrian consumer research}

Regarding the topics, respondents were asked to: a.) fill in a blanket space and provide up to three thematic issues, then assign them to "thematic clusters"; and b.) describe topics they considered both currently dominant in the field and relevant in the future.

The results indicate that Austrian consumer researchers study a variety of topics: $15 \%$ focus on sustainability (e.g. consumer-related emission of pollutants, climate change related practices), $13 \%$ on individual buyer-behavior (e.g. consumer behavior and decision processes), and $10 \%$ on health and nutrition (e.g. pollutant's impacts on health). Between 5-7\% focus on "products" (7\%), "consumer protection" (7\%), "consumer information" $(6 \%)$ and "ethical" or "geographical" issues (5\%). These major themes are followed by a broad range of other issues

\footnotetext{
${ }^{4}$ These, as well as the following median scores $(\mathrm{m})$, are based on a Likert-scale ranging from $1=$ no agreement to $5=$ high agreement. As the standard deviation of all means was rather small (min: 0.7; max: 1.3 in very few evaluations) and because they do not reveal any particularities, they are not reported in more detail.
} 
such as "digitization", "mobility", "participation", "gender", "education", or "security" (all mentioned fewer than five percent). These findings coincide with those of past studies, in which an aspect of thematic plurality for consumer research was found (Helgeson et al., 1984; Oehler \& Reisch, 2012; Peighambari et al., 2016). The results also support the previous finding that "sustainability is a major topic in consumer research" (Oehler \& Reisch 2012, p. 108). It is interesting to note that "financial issues" were rarely mentioned as interesting by the Austrian respondents, while German survey participants (ibid.) have considered this a topic of significant interest.

The respondents were asked to assess current research efforts in several areas (genderrelated aspects, methods and methodology, buyer behavior, consumer education, consumer protection laws, consumer groups, advocacy groups, consumer organizations, information and sustainable consumption) and the need for further research. The respondents indicated that research on the respective areas seems to be insufficient and should, therefore, be intensified (see Table 2).

\section{Table 2: Current Research Efforts and Future Research of Consumer Research in Austria $^{5}$}

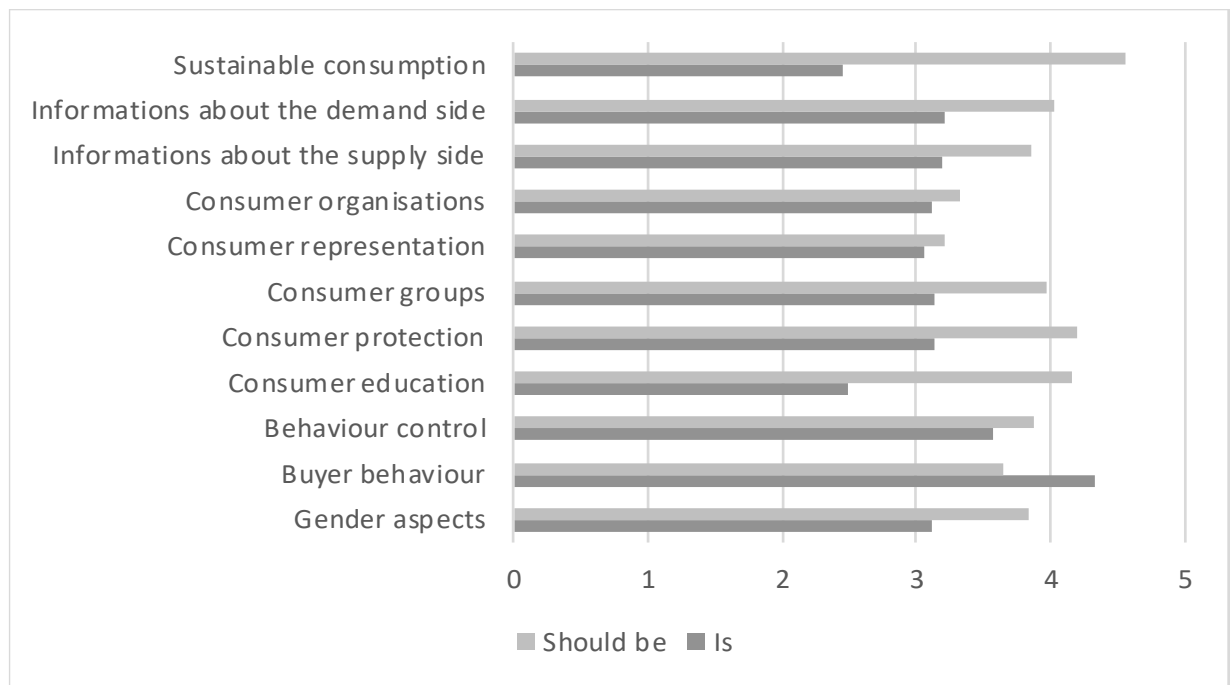

The results show that the respondents perceived consumer education $(\mathrm{m}=2.47)$ and sustainable consumption $(\mathrm{m}=2.45)$ to be the least-studied areas $(\mathrm{m}=2.49)$ and areas which should studied more intensively in future research $(\mathrm{m}=4.65$ respectively $\mathrm{m}=4.16)$. Research on buyer-behavior was cited as an exception, supporting the belief that a greater variety of research topics need to be studied more intensively in the future. The respondents agreed strongly that a sufficient amount of research has been conducted on buyer-behavior $(\mathrm{m}=4.3)$ and, consequently, only a moderately need for further research in this area was expressed $(\mathrm{m}=$ 3.6). This result somewhat supports the efforts of some Austrian consumer researchers, who state that more "critical consumer research" is needed, that goes beyond the buyer-producer

\footnotetext{
${ }^{5}$ Note that, on this item, the number of missing answers was high (ranging from 14 (buyer behavior) to 28 (consumer representation)). This finding may suggest that consumer researchers do not have a good understanding of the field of consumer research in general, a finding that is discussed in more detail in the Discussion and Conclusion section.
} 
paradigm, inherent in much consumer research in marketing and business studies (see section four).

\section{Methods and methodological stances}

Most of the respondents studied consumer-related issues empirically (75\%), and they strongly agreed that consumer research should be empirically grounded $(\mathrm{m}=4.8)$. The respondents used a variety of methods to study consumer-related issues. The predominant methods are "surveys" (43\%), "interviews" (42\%), and "experimental designs" (23\%). Qualitative research designs were used by $17 \%$ of the participants. Furthermore, a broad variety of other methods was mentioned (e.g. "observation", "document analysis", and "case studies", all below 10\%). The variety of applied methods has also been cited in previous literature reviews on consumer research (Helgeson et al., 1984; Peighambari et al., 2016). Notably, only $7.5 \%$ of the respondents stated that they studied consumer-related issues merely by applying theoretical reasoning. These results do not necessarily suggest that Austrian consumer researchers are not interested in developing new and deepening existing theoretical approaches. On the contrary, some researchers pointed out the need for theoretical development in their responses to the open-ended question. This finding mirrors the recent efforts of Austrian scholars who are seeking new ways to theorize consumption (Nessel et al., 2018) and suggests that theory building should be grounded on empirical findings.

The diversity of methods may be associated with the variety of methodological stances held by these researchers, which ranged from positivist to constructivist ones. This interpretation mirrors Hirschman's (1985) suggestion that consumer research is diverse in terms of the methodological approaches applied as well as in scientific styles used. Scientific styles are usually associated with different epistemic stances or worldviews (Slife \& Wiliams, 1995). The methods "hermeneutics" and "experiments" are manifestations of the two most polar extremes of the constructivist and positivist worldviews (Petersen \& Gencel, 2013). As will be shown in the following section, such diverse worldviews may account not only for different scientific styles but also for different conceptualizations of the matter subject as well as the research aims.

\section{Research orientation, conceptualization of the matter subject and research aims}

The results presented in the previous sections highlighted the recent situation of individual consumer researchers. Attention was only occasionally given to a broader assessment of the field (e.g. on research trends). In this section, such assessments are deepened through an exploration of research orientations, conceptualizations of the subject matter and the aims of the research.

From the perspective of the respondents, consumer research in Austria is an inter- and transdisciplinary field of inquiry $(\mathrm{m}=4.3)$. The majority also stated that inter- and transdisciplinary research directions should strongly be progressed in the future $(\mathrm{m}=4.8)$. Consequently, the respondents strongly disagreed with the assertion that consumer research is a monodisciplinary field of inquiry $(\mathrm{m}=1.6)$. What is more, they stated that monodisciplinary courses of inquiry should not be used in future consumer research $(\mathrm{m}=1.4)$. These empirical findings strongly contrast with theoretical informed stances, which suggest that consumer research is not and should only occasionally be an interdisciplinary field (Arndt, 1986; MacInnes \& Folkes, 2010). These results are shown in Table 3. 


\section{Table 3: Research orientations in Austrian consumer research and future directions}

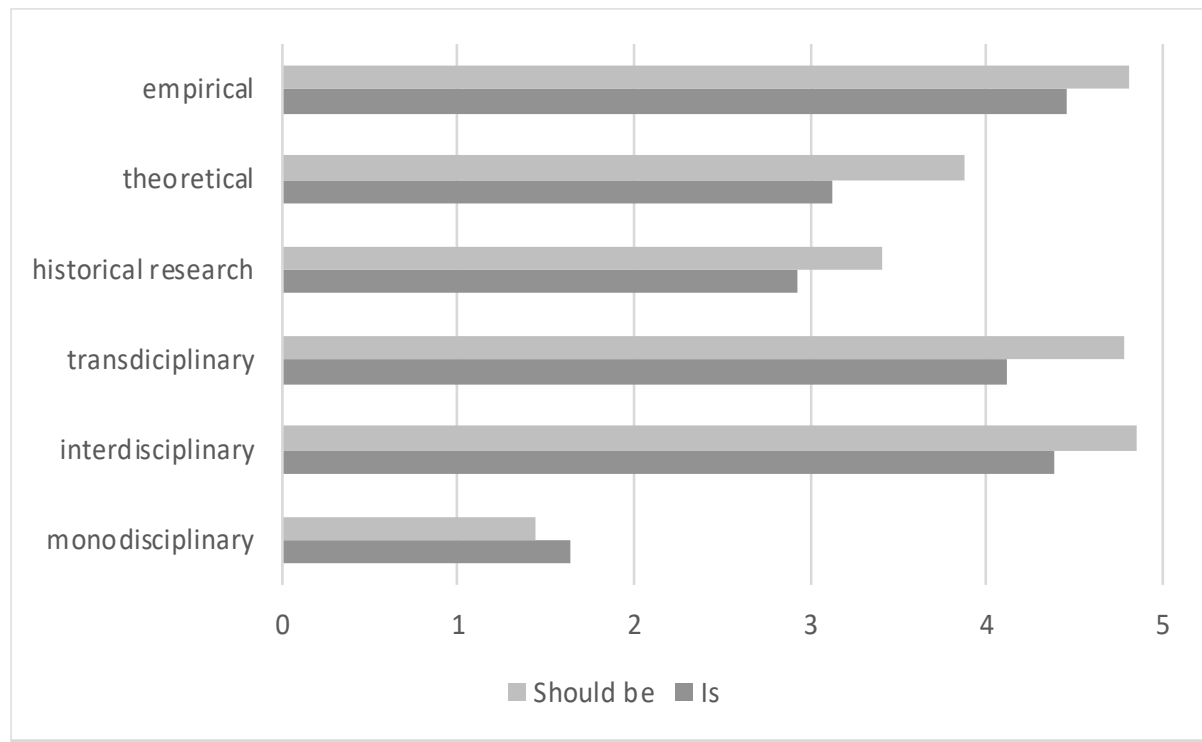

Furthermore, respondents were asked which disciplines they currently see as the main ones in the field and which ones might become more relevant in the future (see Table 4).

Table 4: Disciplines in Consumer Research

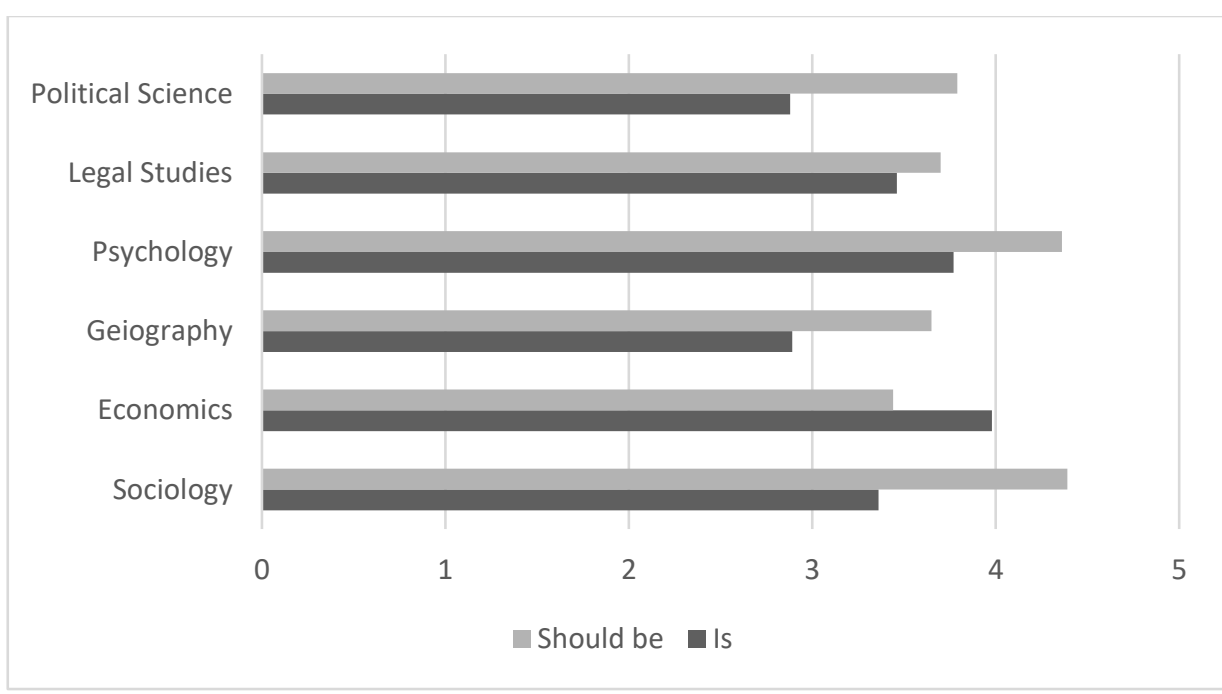

The results indicate that consumer research is perceived as considering geographical (m $=2.89)$ and political $(\mathrm{m}=2.88)$ aspects insufficiently. In future research, respondents stated that nearly all disciplines could be of further relevance, especially sociology $(\mathrm{m}=4.4)$ and psychology $(\mathrm{m}=4.7)$. Economics represented the only notable exception, as it was viewed as sufficiently well-represented in current consumer research $(\mathrm{m}=4)$; respondents perceived economics to be less influential in the future $(\mathrm{m}=3.4)$. This estimation suggests that a more balanced direction in consumer research is needed and that economics is viewed as "too dominant". Because $15 \%$ of the respondents characterized themselves as economists and $2 \%$ as psychologists, this difference in the perceived relevance of future disciplines in consumer research is particularly striking. 
Regarding the conceptualization and theorizing of consumer-related issues, $55 \%$ of the respondents defined consumption as "situational behavior", as proposed by economic approaches, and $79 \%$ conceptualized consumer activities as embedded in a broader societal environment, as proposed by sociological approaches (see Nessel et al., 2019). It was interesting to note that the former perspective was rejected by $35 \%$ of the respondents, and the latter only by $15 \%$, while $55 \%$ appreciated both perspectives. This diversity of the conceptualization of the subject matter is also reflected in the qualitative descriptions. For example, one respondent defined consumer research as "research that blurs the boundary of a narrow buyer-marketperspective and also includes consumer politics and education", while another defined it as a research that, in a narrower sense, asks the questions of "who consumes what, how, when, where and why?". These results indicate that the subject matter of consumer research is contested; they also reflect the aforementioned research paradigms, which range from positivist conceptions to more interpretative ones. Finally, these results can be interpreted as arising from the existence of different research styles or worldviews. This interpretation is underlined by the diversity of aims that scholars associated with consumer research.

The aims of consumer research in Austria were evaluated by asking an open-ended question. The results reveal heterogeneous stances. Some scholars argued for an "instrumental usage" of research, whether it was for the purpose of addressing marketing issues or exploiting economic interests (e.g. "... [consumer research is] to impact and control consumer decisions"). Others linked their research to a societal transformation (e.g. "... [consumer research is] broad societal enlightenment beyond behavior management"). And still others argued for a critical perspective (e.g. "... [in consumer research] one major gap is the lack of critical reflection on inherent moralization accompanying the concepts of consumers"). As with the research directions and the conceptualization of the subject matter, the respondents of this study described highly diverse aims for their consumer research. As these three aspects (aims, conceptualizations and direction) are closely related (Slife \& Williams 1995), the results of this study suggest that they may stem from different scientific stances or worldviews (see below).

\section{Social Relations within the Field of Austrian Consumer Research}

To deepen an understanding of the Austrian field of consumer research, an analysis of the social relations in the field was performed. An initial examination of the data suggested that consumer research in Austria is carried out cooperatively: 60 out of 62 respondents mentioned having had at least one cooperation partner over the last five years outside their own institution. Most cooperation was conducted with researchers employed at universities (92\%). Some scholars also cooperated with private companies (60\%), ministries (47\%), or NGOs (42\%). But a closer look at joint projects reflected the intensity of this cooperation. In this vein, the findings indicated that the academic field still seems to be the most promising context for joint projects $(87 \%)$, although $60 \%$ of the respondents were also carrying out projects with firms, and $32 \%$ with NGOs. One interesting finding was that few joint projects were cited between academic scholars and political institutions. Only $18 \%$ cooperated with ministries; $15 \%$, with an economic chamber and only $5 \%$ with unions. These results indicate that little exchange occurs between academia and political actors in Austria regarding consumer-related issues.

One unexpected finding was that $68 \%$ of the respondents did not know of any network in consumer research. This is even a higher percentage than Oehler and Reisch $(2012,114)$ found for German scholars. Only two networks were mentioned: the European Sensory Network and the Austrian Konsum neu denken network. This finding indicates Austrian consumer researchers rarely join networks, a surprising result considering the background that consumer researchers perceive the field as highly inter- and transdisciplinary. However, many researchers indicated that they were aware of the absence of close cooperation and networks. 
Some of the respondents argued that this represents a major gap in Austrian consumer research which needs to be addressed in the future (see also Pfister \& Nessel 2017). One respondent stated quite strikingly: "The efforts or projects and institutions proceed in isolation, and there is little to no exchange".

\section{Prospects of Consumer Research in Austria}

In the preceding sections, I identified the individual situations and stances of Austrian consumer researchers as well as their general assessments of the field. The possible prospects for the field of consumer research in Austria are described in the following sections.

A major result of this study is that respondents perceived consumer research as highly legally $(\mathrm{m}=4.3)$, politically $(\mathrm{m}=4.4)$, and societally $(\mathrm{m}=4.6)$ relevant. Around $80 \%$ of the respondents also strongly agreed that consumer policy should consider scientific results in decision-making. Consequently, 89\% agreed that consumer policy in Austria should be supported by a scientific advisory board of consumer policy. The recent debate on a so-called "evidence-based consumer policy" (e.g. Hagen et al. 2013) seems, therefore, to be of interest to Austrian researchers. This finding, however, seems to contradict the assessment made by more than 80 percent of these survey respondents (i.e. that the political, societal and legal issues are currently highly relevant to consumer research), because the results of consumer research are rarely applied in Austrian politics and no closer dialogue between the scientific and the political fields exists in this country ${ }^{6}$.

One unsurprising finding was that most respondents of this study expressed worries about the institutional settlement of consumer research in Austria. Respondents indicated that further developments in consumer research as a field should bring together researchers from different disciplines (98\% agreement) and that an independent field of consumer research should be established (77\% agreement). Furthermore, $78 \%$ of the respondents commented on the fact that a departmental chair position in consumer research does not yet exist in the Austrian university system. However, the results indicate that the establishment of such a position is highly contested: $54 \%$ of the respondents agreed that it should be established in consumer law, while $27 \%$ strongly disagreed with such a limited denomination. This, in turn, reflects the perception of consumer research as a multi- or interdisciplinary field and that any monodisciplinary direction within the field (e.g. law or economics) is strongly rejected. It was, however, interesting to note that 17 of the 63 respondents seemed unable to answer the question as to whether consumer research in Austria should be represented by a dedicated chair of consumer law. There appears to be some confusion about consumer research being represented in both politics and academia (see below).

\section{Discussion and Conclusion}

Authors of previous studies approached the field of consumer research by conducting theoretically informed overviews (Antonides \& van Raaij, 1998; Ostergaard \& Jantzen, 2002) or by analyzing the content of scientific articles (Helgson et al., 1984; Peighambari et al., 2016), case studies (Hirschman, 1985), and literature reviews (MacInnis \& Folkes, 2010). In this study, I have taken a different road, conducting a quantitative survey to study consumer researchers. The empirical results presented in this article indicate that Austrian consumer researchers analyze a multitude of thematic issues and use a variety of theoretical and methodological

\footnotetext{
${ }^{6}$ The only exception to this assessment is the fact that the department of consumer protection is in close contact with the state-funded Austrian Consumers' Association VKI. VKI is responsible for the legal representation of consumers in collective suits against firms and for legal class action lawsuits in some areas of infringements.
} 
approaches. These findings suggest that they perceive the subject matter in a variety of ways, associate a variety of goals with consumer research, use different resources to carry out research, and take a variety of epistemological and ideological stances.

Of course, these results must be interpreted carefully as they are based on 63 survey responses and answers to some of the survey questions were missing. Still, to date, this study is one of only two studies that have been carried out to survey the individual characteristics of consumer researchers (see Reisch \& Öhler, 2012), and the first to study the consumer researchers' assessments of this scientific field and stances towards consumer policy. Reisch and Öhler's (2012) survey of consumer researchers in Germany provided a starting point for this research, which was extended by including a more varied sample and asking new questions to shed light on consumer researchers' individual characteristics, assessments of the field, and stances towards politics. That said, the approach taken in this study not only contributes valuable additional knowledge about the Austrian field of consumer research but also reveals some practical problems that can be encountered and solutions that can be applied when entering the relatively unknown field of consumer researchers in Austria and other countries (see section two).

Although the results of this study must be interpreted with care, it is notable that they support the findings of previous studies (MacInnis \& Folkes, 2010; Peighambari et al., 2016), which show that consumer researchers analyze a broad range of topics and use a variety of methods. They also support the suggestion that consumer research includes different research styles (Hirschman, 1985) and that consumer researchers possess different financial and human resources (Oehler \& Reisch, 2012). These findings differed from those of previous suggestions (Arndt, 1986; MacInnes \& Folkes, 2010) in that the respondents stated that the consumer research field is, and should be, an inter- and transdisciplinary one. Unlike the German respondents to Oehler and Reisch's (2012) survey, the Austrian study respondents seemed more skeptical regarding the adoption of a behavioral science perspective to study consumer behavior. This result is particularly interesting considering current international developments which show that behavioral science perspectives are becoming more and more important in the field of consumer research as well as in consumer policy (see below).

In Austria (Hübner et al., 2018; Jonas \& Hassemer, 2018; Nessel et al., 2018), as well as in the international context (Deighton, 2007; MacInnes \& Folkes, 2010), there are ongoing discussions about how consumer research could become a more closely integrated scientific field. This study revealed some shared characteristics of Austrian consumer researchers, laying a foundation for closer cooperation within the field. Above all, the respondents strongly agreed that consumer research should be based on empirical evidence and inter- and transdisciplinary in nature. Respondents emphasized the need to establish an institutional environment which would foster a more closely integrated scientific field that includes several scientific perspectives. Hirschman's (1985) suggestion was echoed by several respondents, i.e. that the diversity and variety of consumer research may serve as a fertile ground for innovations to study consumer-related issues. They accordingly agreed that it is important to use different research styles to better understand the many facets of consumer-related issues. For this reason, these styles should equally be part of the field and acknowledged by consumer policymakers.

However, the results also reveal potential obstacles that could hinder attempts to make consumer research a more closely integrated field. Above all, facing the challenge to overcome somewhat diverse epistemological and methodological stances, which range from positivist to interpretative ones, could be difficult. These stances may arise from the fact that diverse worldviews contribute to different conceptions of the subject matter, research aims, and research styles in consumer research (see Slife \& Williams, 1995 for a similar argument). Diverse epistemological and methodological stances may also hinder integration in that they 
deepen different "camps" among consumer researchers (Simonson et al., 2001). This interpretation may explain why Austrian consumer researchers seem to have, on one hand, a clear understanding about the desirable future directions of the field (e.g. that the field should be composed of different disciplines; that sustainability is an important future research topic; or that political actors should support consumer researchers) but, on another hand, seem to lack a general understanding of the current situation of both their colleagues and the field. In this case, it is hardly surprising that the respondents to this survey perceived the lack of cooperation and exchange with their colleagues, a finding which seems to be characteristic for consumer research fields in other countries as well (Simonson et al., 2001).

One unsurprising finding was that some Austrian scholars worried about efforts that were being made to build a more coherent field of research from within, albeit they would strongly appreciate such efforts. I suggest that by encouraging a closer dialogue between consumer researchers and fostering a better understanding of their diverse methodological, epistemological and theoretical perspectives, they may be able to more efficiently apply their insights and emphasize their relevance to consumer policy. This is not to say that the differences within this field of research are illusionary. Instead, these differences must be acknowledged within the field and by those creating consumer policies. On one hand, these differences indicate deeper conflicts, as different groups within the field compete for both material resources and the power to establish a legitimate definition of consumer research. International debates on "evidence-based consumer policy" are notably dominated by behavioral scholars (Hagen et al., 2013; Reisch \& Sandrin, 2015; Reisch \& Zhao, 2017), and "behavioral insight teams" have influenced the consumer policy of the European Commission with increasing frequency. However, consumer policy can draw on a wide array of scientific approaches and methods and, consequently, should not be restricted to a single scientific perspective (see also Nessel et al., 2018). On the other hand, the highlighted differences provide reasons to strengthen cooperation, encourage dialogues, and, above all, foster a common understanding of consumer research that is as diverse and flexible as its subject matter.

The empirical findings of this study, furthermore, suggest that many consumer researchers in Austria see a need to garner more "external" political support to build a more closely integrated field and increase cooperation. The overwhelming majority of the respondents to this survey expected political actors to provide both more ideal and financial resources to support this scientific field, whether it was in the form of more research funding (of course), institutionalizing (!) and funding a chair for consumer research, or establishing a scientific advisory board for consumer policy, which does not yet exist in Austria.

As the recent developments and experiences in German consumer research have shown, political support can indeed promote deeper dialogue among consumer researchers or, at least, allow them to exchange different perspectives about the field, consumer policy and consumer research. In Germany, the Ministry of Justice and Consumer Affairs as well as some federal initiatives promote strategies to bring consumer researchers with policy makers into contact by means of holding frequent workshops and conferences, installing a nationwide network of consumer research, and regularly funding projects to deepen the scientific knowledge about consumer-related issues.

Despite the expectations of the Austrian respondents, it was interesting to note that political actors in Austria still seem hesitant to promote strategies that can bring the scientific community together with policymakers. Hence, in Austria, certain scholars have founded a network on consumer research in cooperation with the Austrian Chamber of Labour in Vienna (Konsum neu denken), which has thus far held four associated conferences (see Pfister \& Nessel, 2017). But few members of the broader community of consumer researchers know of this initiative. This finding led me to identify a more general question that is relevant to both 
the scientific and political fields: Do external political efforts support advancements in the field which can then support political decisions or are alternative or complementary efforts from within the field necessary?

The effects of external political efforts and internal, field-specific efforts to promote cooperation and theoretical and empirical developments in the field of consumer research have yet to be analyzed in more detail, in Austria and elsewhere. As proposed in this article, the results of surveys conducted among consumer researchers may contribute to such evaluations, as they provide a better understanding of the field and a basis for scientific and political actors to foster cooperation by acknowledging that studies of consumption require diverse perspectives. In the future, such surveys may be accompanied by surveys conducted on consumer policymakers to assess their expectations about the scientific consumer research community. A lesson which can be learned from the Austrian case is that a deeper dialogue between consumer researchers themselves is needed to foster more mutual understanding, as well as between them and consumer policymakers. This dialogue may finally set the stage for an "evidence-based consumer policy" which is founded upon all available consumer research insights, rather than being restricted to behavioral insights alone.

\section{REFERENCES}

Antonides, G., van Raaij, W. F. (1998). Consumer behavior: A European perspective. Chichester: John Wiley \& Sons.

Arndt, J. (1986). Paradigms in consumer research: A review of perspectives and approaches. European Journal of Marketing, 20, 23-40.

Arnould, E. A. and Thompson, C. J. (2005). Consumer Culture Theory (CCT): Twenty Years of Research. Journal of Consumer Research, 31, 868-882.

Deighton, J. (2007). From the editor. The territory of consumer research: Walking the fences. Journal of Consumer Research, 34, 279-282.

Hagen, K., Micklitz, H.-W., Oehler, A., Reisch, L. \& Strünck, C. (2013). Check consumer policy and consumer participation: recommendations for evidence-based consumer policy. Journal of Consumer Protection and Food Safety, 8, 61-66.

Helgeson, J. G., Kluge, A., Mager, J. \& Taylor, C. (1984). Trends in consumer behavior literature: A content analysis. Journal of Consumer Research, 10, 449-454.

Hirschman, E. C. (1985). Scientific style and the conduct of consumer research. Journal of Consumer Research, $12,225-239$.

Hübner, R., Ukowitz, M. \& Lerchster, R. (2018). Netzwerk Konsum der Zukunft. In S. Nessel, C. Fridrich, R. Hübner \& N. Tröger (eds.), Multiperspektivische Verbraucherforschung: Ansätze und Perspektiven. Wiesbaden: VS (231-254).

Jonas, M. \& Hassemer, S. (2018). Möglichkeiten und Grenzen einer Verbraucherforschung in Österreich vor dem Hintergrund gesellschaftstheoretischer Diagnosen: Eine Interpretationsskizze auf der Basis von Gesprächen mit Expertinnen und Experten. In S. Nessel, Ch. Fridrich, R. Hübner \& N. Tröger (eds.), Multiperspektivische Verbraucherforschung: Ansätze und Perspektiven. Wiesbaden: VS (173-197).

MacInnis, D. J. \& Folkes, V. S. (2010). The disciplinary status of consumer behavior: A sociology of science perspective on key controversies. Journal of Consumer Research, 36, 899-914.

Miller, D. (1995). Acknowledging consumption: A review of new studies. London: Routledge.

Pfister, S. \& Nessel S. (2017). Konsum neu denken - multiperspektivische Verbraucherforschung. Tagungsbericht und Terminaviso. GW Unterricht, 145, 53.

Nessel, S., Tröger, N., Fridrich, Ch. \& Hübner, R. (2018). Dimensionen, Ansätze und Perspektiven einer multiperspektivischen Verbraucherforschung. In S. Nessel, Ch. Fridrich, R. Hübner \& N. Tröger (eds.), Multiperspektivische Verbraucherforschung: Ansätze und Perspektiven. Wiesbaden: VS (15-51).

Oehler, A., Reisch, L. A. (2012). Sie lebt! Zur Verbraucherforschung im deutschsprachigen Raum: Eine empirische Analyse. Journal of consumer protection and food safety, 7, 105-115.

Østergaard, P. \& Jantzen, Ch. (2002). Shifting perspectives in consumer research: From buyer behaviour to consumption studies. In S. Beckmann \& Elliott, C. H. (eds.), Interpretative Consumer Research. Paradigms, Methodologies and Applications. Copenhagen: Copenhagen Business School Press (9-23).

Peighambari, K., Sattari, S, Kordestnai A. \& Oghazi P. (2016). Consumer behavior research. A synthesis of the recent literature. Sage open. doi/abs/10.1177/2158244016645638 (accessed 15.10.2019). 
Reisch, L. \& Sandrini, J. (2015). Nudging in der Verbraucherpolitik. Ansätze verhaltensbasierter Regulierung. Baden-Baden: Nomos.

Reisch, L. \& Zhao, M. (2017). Behavioural economics, consumer behaviour and consumer policy: State of the art. Behavioural Public Policy, 1, 190-206.

Simonson, I., Carmon, Z., Dhar, R., Drolet, A. \& Nowlis S. (2001). Consumer research: in search of identity. Annual Review of Psychology, 52, 249-275.

Slife, B. \& Williamson, R. N. (1995). What's Behind the Research? Discovering Hidden Assumptions in the Behavioral Sciences. Thousand Oaks: Sage Publications.

Tukey, J. W. (1977). Exploratory data analysis. Reading: Addison-Wesley.

Warde, A. (2005). Consumption and Theories of Practice. Journal of Consumer Culture, 5, 131-153. 